\title{
A FRAMEWORK FOR MORPHING CAPABILITY ASSESSMENT
}

\author{
Carlos E. S. Cesnik* \\ Department of Aerospace Engineering \\ The University of Michigan, Ann Arbor, Michigan \\ Howard R. Last $^{* *}$ and Christopher A. Martin ${ }^{* * *}$ \\ Science \& Technology Division \\ Institute for Defense Analyses, Alexandria, Virginia
}

\begin{abstract}
This paper describes a framework and process for assessing vehicle morphing capability in the context of a desired mission scenario, vehicle performance needed to realize the mission, and the state changes and potential technology advancements required to enable that vehicle performance. The process is subdivided into two parts: Morphing Concept Assessment and Morphing Concept Development Levels. This process is applied to an air vehicle to illustrate its use. While the paper focuses on air vehicles, the framework is intended to be independent of vehicle operational media (e.g., air, water, land, space). Even though many aspects of the assessment process are subjective, it provides a common framework for identifying, discussing, and evaluating critical vehicle and technology issues. It also provides a foundation for development of vehicle and technology research and development programs.
\end{abstract}

\section{INTRODUCTION AND BACKGROUND}

During the past decade, the multidisciplinary field of smart materials and structures experienced rapid growth in terms of individual technologies and applications. The structures demonstrated in these research and development (R\&D) programs utilized integrated sensors, actuators and controllers to achieve limited shape change in response to environmental and operational conditions. Although largely successful, the full potential of smart system capabilities was not realized and the concept of "morphing" was proposed to take the next step forward.

Morphing became thought of as a revolutionary concept to allow for development of improved and new air-vehicle mission capabilities. Such capabilities

\footnotetext{
Associate Professor of Aerospace Engineering, Associate Fellow AIAA. Member, AHS.

** Research Staff Member.

${ }^{* * *}$ Research Staff Member, Senior Member, AIAA.

Copyright $(2004$ by Carlos E. S. Cesnik, Howard R. Last, and Christopher A. Martin. Published by the American Institute of Aeronautics and Astronautics, Inc., with permission.
}

might include the ability to perform current, dissimilar missions with fewer vehicles or the ability to perform completely new missions. These new capabilities were to be achieved via large shape changes leading to superior and/or new vehicle performance characteristics relative to current aircraft. During several meetings and small workshops, the concept of morphing evolved beyond shape change as the only way a vehicle can adapt to changes in environmental and operational conditions. Science and technology (S\&T) programs for the Services and the National Aeronautics and Space Administration (NASA) began to be revitalized by these new ideas.

To further capitalize on these recent developments, the Office of Naval Research (ONR) and Defense Advanced Research Projects Agency/Defense Sciences Office (DARPA/DSO) co-sponsored an In-Flight Reconfigurable Aircraft (IFRA) Workshop in December of 2002. The workshop brought together a multi-disciplinary team of government, university, and industry specialists to

- Establish a common vision and understanding of how morphing might benefit future military air vehicle capabilities

- Identify critical path technologies and analytical tools to achieve such new capabilities

- Draft a technology/tool maturation timeline with rough order of magnitude costs to achieve such new capabilities

- Determine potential areas for coordination and leveraging of S\&T investments based on current efforts and technology readiness levels ${ }^{1}$

The workshop focused solely on vehicle shape change for fixed-wing air vehicles up to high subsonic flight conditions.

In order to achieve the workshop objectives, a clear and consistent definition of morphing was required. While there are many definitions of "morphing" in use today, for the workshop and in this paper, "morphing" is defined as a capability to provide superior and/or new vehicle system performance by tailoring the vehicle's state to adapt to the environment and multi-variable mission roles, where: 
- Performance includes agility/maneuverability, range, speed, acceleration, radar cross-section, payload/weapons and sensors, etc.

- Vehicle state includes physical geometry/ configuration, mechanical properties, electromagnetic properties, etc.

- Environment includes external operational conditions such as temperature, humidity, shock, vibration, electromagnetic, etc.

During the IFRA workshop planning, the need to develop metrics, a method to assess morphing capabilities, and a means to represent the assessment information was identified. Initial morphing capability assessment method development efforts were based in part on the Air Force's approach to develop autonomous unmanned aerial vehicle (UAV) control intelligence metrics ${ }^{2}$. The intent was, and still is, to develop a framework to assess morphing capabilities to aid in program planning and in tracking advancement of morphing $\mathrm{R} \& \mathrm{D}$ projects. The work presented in this paper is the result of the on-going effort to develop a framework for a "Morphing Capability Assessment" (MCA) tool/process.

The establishment of a general morphing capability assessment method is a desirable long-term goal and could prove useful to program managers, system developers, and science and technology researchers. As morphing vehicle and technologies R\&D efforts continue, ideas and information need to be communicated effectively and efforts need to be coordinated across organizations. This need to plan and coordinate $\mathrm{R} \& \mathrm{D}$ efforts has helped motivate the development of a morphing capability assessment framework.

Currently, there are many approaches used to convey the potential impact of developing morphing aircraft and technologies on mission capabilities. Consequently, comparing and contrasting morphing vehicle and technology programs is challenging. Moreover, morphing capability should not be limited to air vehicles. Conceptually, vehicles operating in any environment (i.e., air, land, water, space) or any combination thereof may morph to achieve desired vehicle attributes or states. As the types of potential morphing vehicles and perceived required technologies increase, assessing the impact of morphing on capabilities and identifying technical needs will become more difficult.

Since most current morphing efforts are focused on air vehicles and technologies, this paper applies the proposed morphing capability assessment tool to air vehicles. However, the proposed framework is general enough to address vehicles operating in different media. Based on the definition stated previously, a morphing capability assessment process should systematically consider the vehicle's ability to effectively complete a desired mission based on changes in vehicle performance. Also, technology advancements that enable one or more vehicle components to change the vehicle's state leading to desired performance changes should be assessed in a self-consistent manner.

\section{Proposed Morphing CAPABILITy AsSESSMENT PROCESS}

Developing a MCA process is a complex task and the connection between each of the following areas must be represented in a self-consistent and useful manner:

- Mission capabilities and required vehicle performance characteristics;

- Performance characteristic changes and vehicle state changes;

- Vehicle state changes and technology advancements.

At the end, the complete framework should support the selection of directions for morphing developments based on understanding the links among new mission capabilities, system performance changes, system state changes, and enabling technologies. The proposed MCA process is composed of two main parts: (i) the Morphing Concept Assessment (MCoA) process and (ii) the Morphing Concept Development Levels (MCDL) chart.

\section{Morphing Concept Assessment (MCoA)}

The MCoA process begins with the premise that a given mission has been conceived and ends with an assessment of different potential morphing solutions and related technologies required to accomplish it.

There are three very distinct but intimately related steps in the MCoA process, as shown in Figure 1. In the first step, the relationship between mission scenarios and required vehicle performance metrics is established. Generally, mission scenarios developed by the users will identify key vehicle performance characteristics required to accomplish those scenarios. The connection between the performance parameters of either existing or proposed vehicle and mission-defined key vehicle performance characteristics is represented on a performance-space "spider plot", as schematically illustrated in Figure 2. This plot allows comparison among performance characteristics of current, newly proposed, and/or envisioned vehicles. It also provides a clear illustration of advancements needed in vehicle performance to actually fulfill the mission. It should be expected here that new mission-defined vehicle performance characteristics would contain contradictory requirements relative to current vehicle capabilities, e.g., combining long endurance and high 
dash speed requirements in case of an aircraft, so that feasible solutions can only be achieved by significant vehicle state changes.

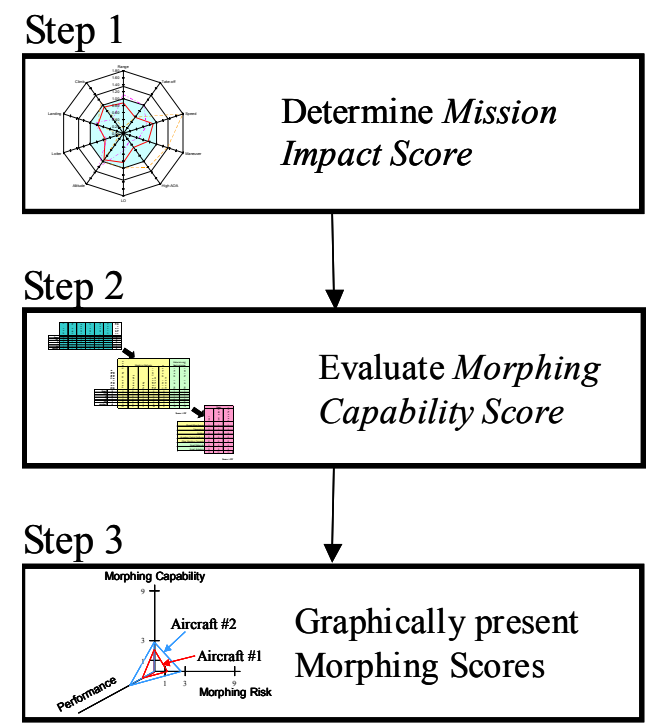

Figure 1-Three basic steps of the MCoA framework

Using the information from the performance space, a compound number can be determined that represents the Mission Impact Score (MIS) for the given vehicle (indicated in the table at the bottom of the spider chart-Figure 2). The MIS can be determined based on different combinations of normalized performance parameters, e.g., simple mean, geometric mean, rootmean-square, weighted mean, etc. Advantages and shortcomings of some of these means are discussed in the example section.

The defined performance parameters must be related to vehicle state changes, the means to achieve such changes, the enabling technologies available/to be developed, and their corresponding technology development risks (including costs). These result in four sub-steps that make up the core of the second step in the MCoA process. The process was developed based on a modified Quality Functional Deployment (QFD) approach.

Figure 3 illustrates the four sub-steps. First, the sensitivity of different state change parameters is mapped against key performance metrics determined from the MCoA Step 1. For this, already existing and new design tools are required that can perform the trade offs between morphing features. In the aircraft example, this reflects how wing area, aspect ratio, camber, etc. can affect vehicle performance parameters such as loiter time, range, dash speed, etc. At the end of this sub-step, the most effective state change parameters are ranked. Using these, morphing methods/schemes that can achieve those state changes are measured for effectiveness in performing the desired changes. These state changes can then be related to/linked to appropriate technologies necessary to achieve the required state changes. The fourth sub-step uses the selected state changes/technology pairs for a risk assessment based on cost, complexity, manufacturability, maintainability, etc. Finally, a compound number, denoted Morphing Capability Score, is obtained. Procedures to reduce the effect of individual bias to this measure and its detailed definition will be discussed in the following section.

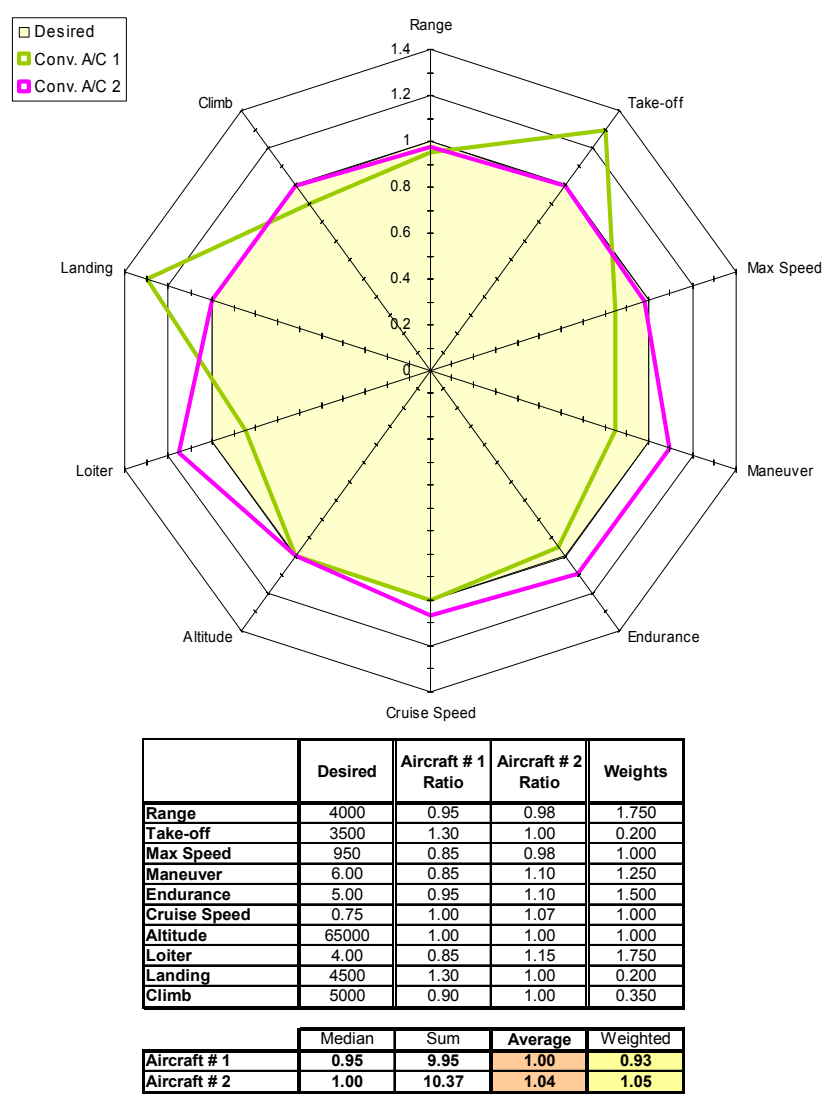

Figure 2-MCoA Step 1: determination of the Mission Impact Index

A graphical way of presenting the relative morphing capability of the compared vehicles and technologies is shown in Figure 4. For MCoA Step 3, the three morphing scores; the Morphing Performance Impact, the Morphing Capability Score, and the Morphing Risk Indicator; are plotted on a three-axis graph shown. 


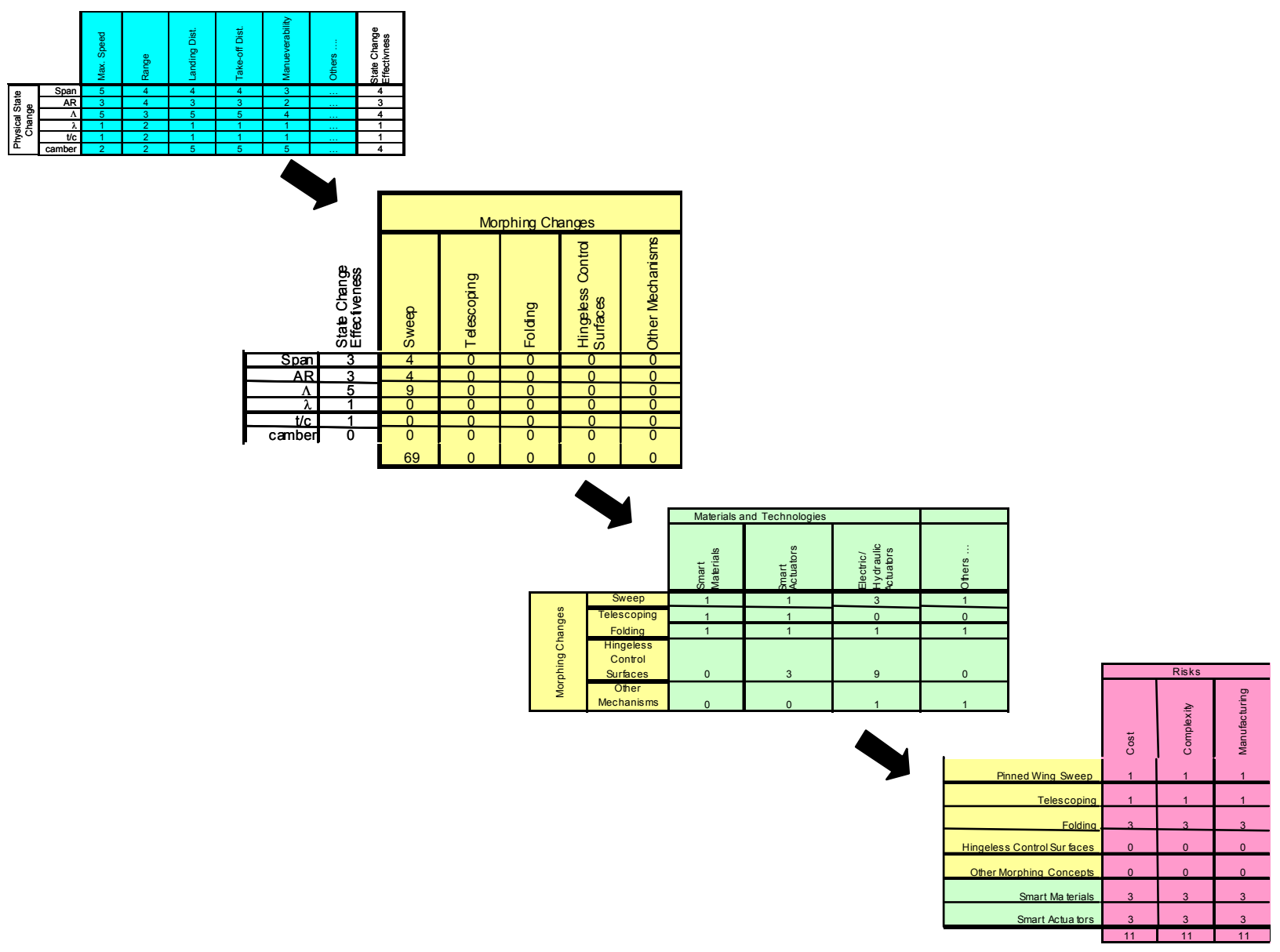

Figure 3-MCoA Step 2: determination of the Morphing Capability Score

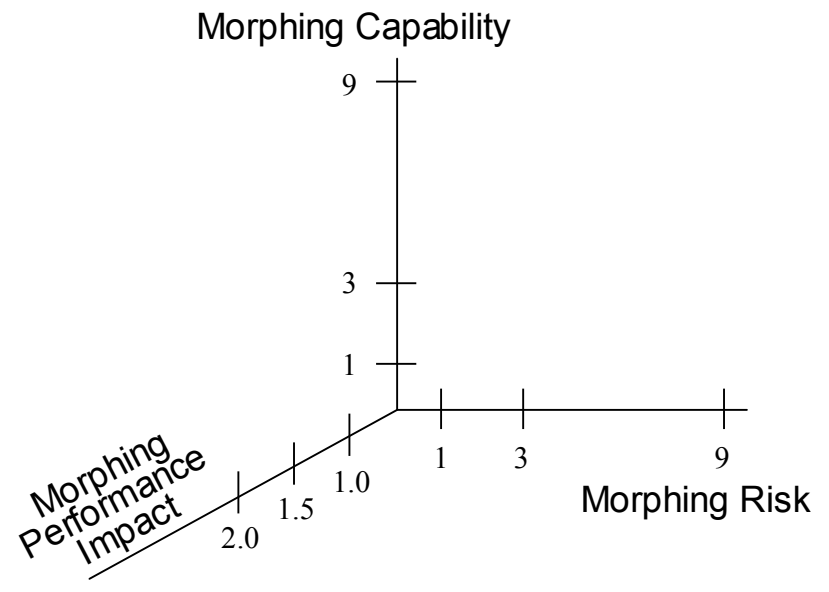

Figure 4-Plot representation used in Step 3 of $\mathrm{MCoA}$

\section{Example on the Usage of MCA}

To illustrate the proposed assessment process, consider that an advanced aircraft designed to perform a strike/attack mission is sought (a type of mission that might have been desirable in the 1970's). The objective is to accomplish an existing mission (i.e., strike/attack) with improved effectiveness (e.g., deeper strike range, extended time on station, and increased vehicle maneuverability).

A set of performance metrics that a potential new aircraft must fulfill is derived from the mission requirements. Table 1 summarizes the mission performance metrics for this example.

Consider two notional aircraft as contenders to enable this new mission. Aircraft \#1 is a supersonic, fighter/attack aircraft (with features similar to the General Dynamics F-111). Aircraft \#2 is another fighter/attack aircraft similar to Aircraft \#1 but with a particular morphing feature. (This second aircraft is based on the F-111 Mission Adaptive Wing airplane 
from the Advanced Fighter Technology Integration (AFTI) program. The AFTI F-111 aircraft advanced leading and trailing edge control surfaces ${ }^{3}$ to actively control wing shape to improve flight performance.) Both aircraft have variable sweep wings. Aircraft \#2 has adaptive leading and trailing edge control surfaces that allow smooth variable camber wings and contain the control system required to adjust the wing in response to different flight conditions. The conventional control surfaces on each wing are replaced by gapless surfaces that allowed the wing shape of Aircraft \#2 to be optimized for landing, cruise, and high speed dash. As an example, Figure 5 shows how the AFTI F-111 wing shape changed for different lift versus drag requirements. While not an example of a vehicle with comprehensive morphing capabilities, it provides an initial test case to demonstrate the utilization of the MCA process.

Considering first the MCoA, the three steps to be applied to this example can be summarized as:

Step 1. Assess Vehicle Performance
Step 2. Determine Morphing Capability Score and Risk

Step 3. Graph Morphing Scores

After translating the mission into desired performance metrics, the first step in the proposed MCoA process is to determine how well the vehicles under consideration, in our case Aircraft \# 1 and \#2, perform against those metrics. Because most of the principal metrics have different units, a normalized ratio of the vehicle performance parameter relative to the desired performance is made. The individual aircraft ratios are then plotted on a spider plot (Figure 6) against the desired mission performance characteristics. The table under the plot shows the given mission performance characteristics and the resulting ratio for Aircraft \# 1 and Aircraft \#2. As may be seen from the plot, Aircraft \#2 improves on the performance achieved by Aircraft \# 1 with respect to range, loiter time, and maximum speed, and, in some cases, greatly outperforms it for the given mission metric.

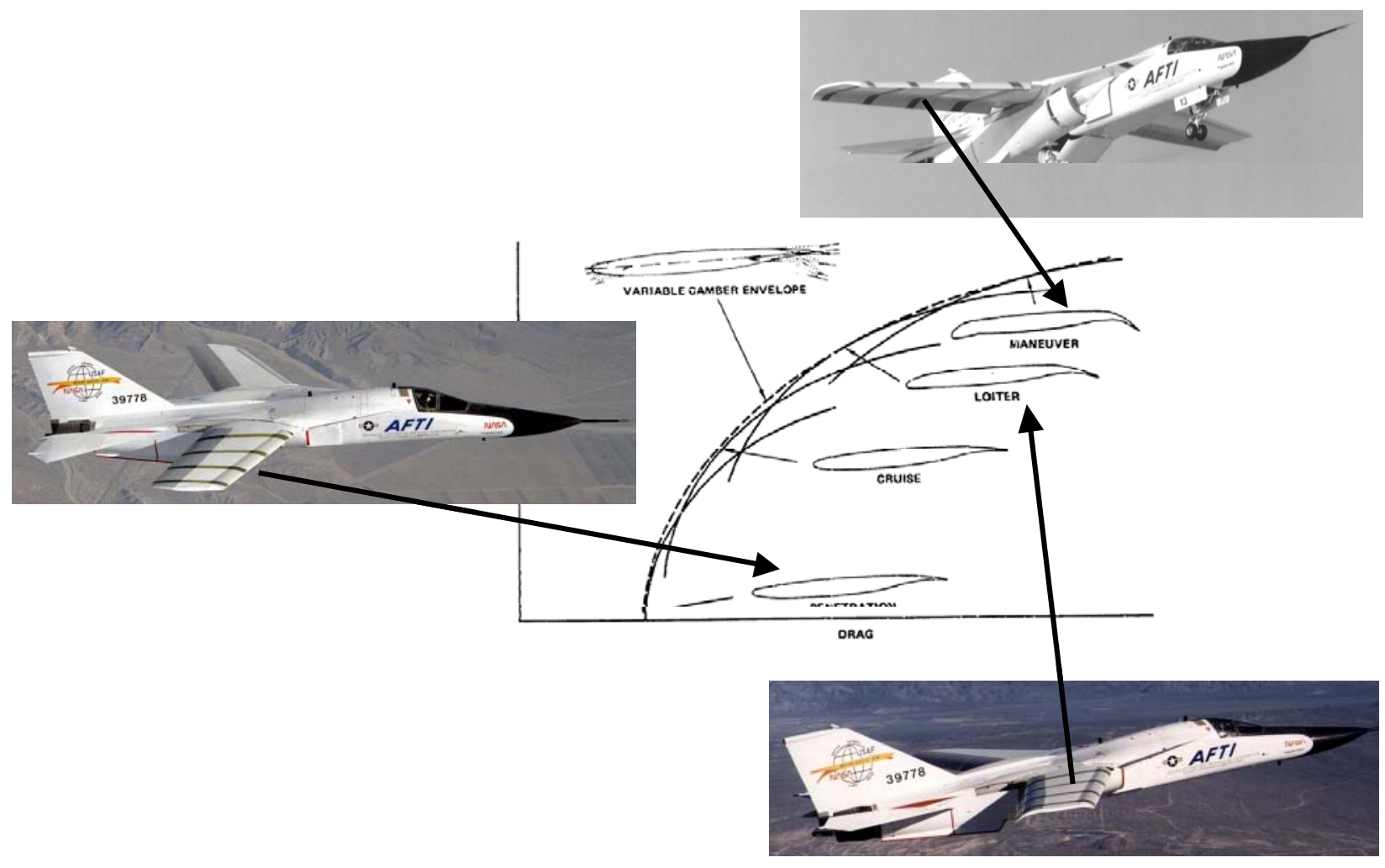

Figure 5-Description of AFTI F-111 
Table 1. Desired Attack/Loiter Mission Performance Metrics

\begin{tabular}{|l|c|}
\hline Mission Performance Parameters & Desired Value \\
\hline Range (NM) & 4,000 \\
\hline Take-off Distance (ft) & 3,500 \\
\hline Maximum Speed (knots) & 950 \\
\hline Maneuver Limit (g's) & 6 \\
\hline Endurance (hr) & 5 \\
\hline Cruise Mach No. & 0.75 \\
\hline Maximum Altitude (ft) & 65,000 \\
\hline Loiter Time (hr) & 4 \\
\hline Landing Distance (ft) & 4,500 \\
\hline Climb Rate (ft/sec) & 5,000 \\
\hline
\end{tabular}

To arrive at the Mission Performance Impact score, the vehicle score that describes how the aircraft performs the given mission, a weighted average can be used for the performance ratios. For the example chosen, both a simple average and a weighted average calculation were done to show why the weighted average is currently the preferred method to calculate MPI. If a simple average is used, the MPI for Aircraft \#2 is 1.04 while that for Aircraft \#1 is 1.00 . What these numbers imply is that Aircraft \#2 would outperform, on the whole, the desired mission performance goals by $4 \%$ while Aircraft \#1 meets the desired mission performance criteria. While a well-selected set of performance metrics characterizes the desired mission, not all metrics have the same mission impact. In fact, the MPI score can be skewed because one performance metric is greatly different from what is required. To address this issue, a weighted average function is used to ensure the mission performance metrics that are most critical count the most towards the MPI score. To determine the weights, the evaluator assigns an importance or weight to each metric by setting the higher weights for attributes that are significant and reducing the weight for less important ones. A numerical example of how the standard average calculation can misinterpret the relative performance effectiveness of each aircraft is shown in the two left columns in the table of Figure 6.

It is assumed for this strike/attack mission that the range of the aircraft is a much more important metric than the takeoff and/or landing distances (within reason). This is reflected in the choice of weights: 1.75 for range and 0.20 for takeoff/landing distance. The rankings show that if simple average were used to calculate MPI, Aircraft \#1 and \#2 would be rated very closely. This is not a true reflection of each aircraft's ability to meet the define mission scenario. Using the weighted average, on the other hand, gives Aircraft \#2 the higher MPI value, 1.05 versus 0.93 for Aircraft \#1. The higher MPI indicates that Aircraft \#2 better satisfies the performance metrics that represent the desired mission. It clearly scores higher in the categories that were deemed more important, and, therefore, assigned higher weights: range, loiter, endurance and maneuver capability for this particular example.

Step 2 in the MCoA provides information on what physical characteristics are necessary and what technologies may be applied to achieve the performance results of Step 1. As previously described, Step 2 applies a modified QFD process to the morphing vehicles to discern the benefits and risks associated with incorporation of different morphing technologies. The QFD process was developed originally to help multidisciplinary organizations focus on customer requirements ${ }^{4}$. The qualities important in identifying customer needs, namely non-evenly distributed scoring to differentiate between "low-medium-high" impact, technology identification, and relative importance recognition, are the same as those necessary to quantify morphing capability.

For this example, a three-step QFD analysis is applied. The first part involves determining the effectiveness of selected state changes on individual performance metrics; this was established in Step 1, and is, therefore, linked directly to the mission effectiveness. Values from 1 (lowest) to 5 (highest) are used to quantify the impact. For the current example, physical characteristics that could be changed by morphing the wing are the wing span, wing aspect ratio (AR), sweep angle $(\Lambda)$, taper ratio $(\lambda)$, wing thicknessto-chord ratio $(t / c)$, and wing camber. The scores for each physical state are determined through a combination of numerical simulations, knowledge of the morphing vehicle being evaluated, and an understanding of how the physical changes affect each of the selected performance metrics. This is summarized in Figure. 7. The simple average of the scores for each state change effectiveness rating (right column in Figure 7) will be used as the weight in the calculation of the Morphing Capability Score. For Aircraft \#1 and \#2, the span change, sweep angle, and camber change were rated high and given average scores of 4. Taper ratio and thickness-to-chord ratio were not as important to the given mission and were rated only as 1 , the lowest value. The average of these values are then placed in the left most column of the QFD matrix for Part 2 (see Figure 8). 


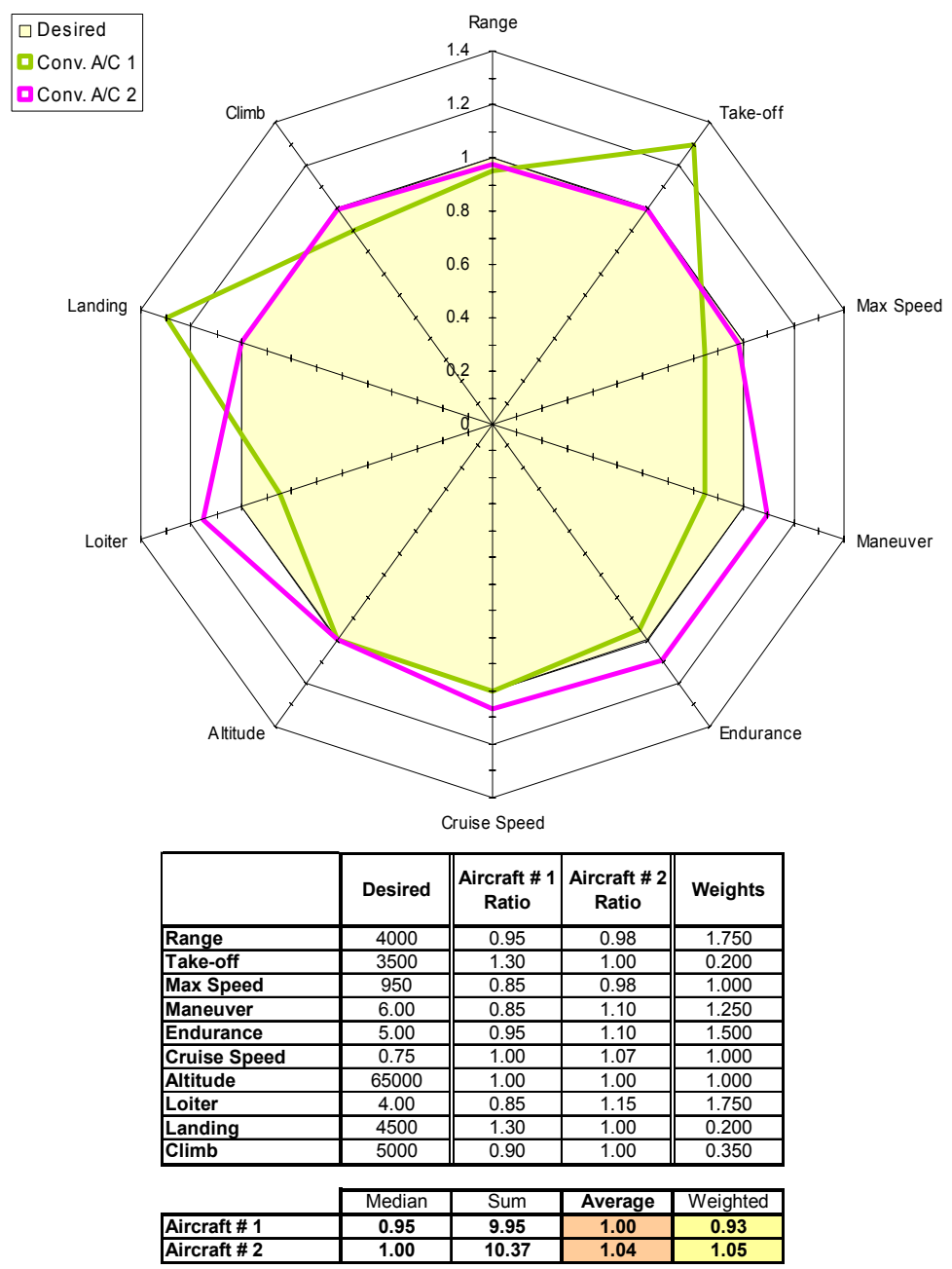

Figure 6-MCoA Step 1: Vehicle performance metrics

The next step represents the connection between morphing methods and technologies to the physical state changes. This is illustrated in Figure 8 for both example aircraft. The means and methods used to achieve morphing are placed in the vertical columns and scored with a $0,1,3$, or 9 depending on whether they make zero, small, moderate, or large contributions to the physical state change of the vehicle. Returning to the example, Aircraft $\# 1$ and Aircraft $\# 2$ share a common characteristic, namely a variable sweep wing. Aircraft \#2, though, varied from $\# 1$ in that it has variable camber leading and trailing edge control surfaces that could be used to more precisely tailor the wing shape for landing, take-off, cruise, and dash. This difference is reflected in the "Hingeless Control Surface" column, where the value is zero for Aircraft $\# 1$ and 9 for the Aircraft \#2. The capability score given to each aircraft is a normalized average with the normalizing value being 9 times the number of nonzero boxes in the QFD matrix, i.e., the maximum score possible. As the scores show, Aircraft \#2 receives a higher MCS. This was expected due to the inclusion of the highly adaptive leading and trailing edge control surfaces. As morphing capabilities and use of smart structures increase, the MCS scores will rise above the "low" value seen in this example.

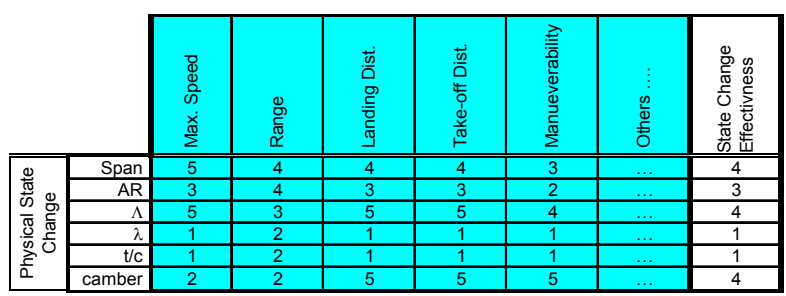

Figure 7-MCoA Step 2/Part 1: Mission impact assessment of selected physical state changes

While knowing that an aircraft has a higher morphing capability is important, an assessment of the risk in development and operations would also provide 
much needed information to the program manager selecting which concept to fund or to system developers seeking to identify risk early in a program. This is the core of Part 3 of the MCoA process. The risk assessment is done using a similar QFD approach to that in Part 2. For the risk assessment, the items of interest, i.e., mechanisms and technologies, are placed in the left column as shown in Figure 9. They are compared to areas of risk including but not limited to cost, schedule, and manufacturing. The columns are then multiplied together, summed, and the normalized average is determined (as in Part 2) to arrive at the risk score. As would be expected for the aircraft selected in our example, Aircraft \#2 showed a much higher risk score than Aircraft \#1 due to the variable leading and trailing edges. The higher risk does not necessarily mean that the project is not warranted, only that there are aspects of the cost, complexity, schedule, and/or manufacturing that require attention and vigilance to reach successful completion. The risk analysis portion of the MCA framework is meant to identify technology areas that require extra attention.

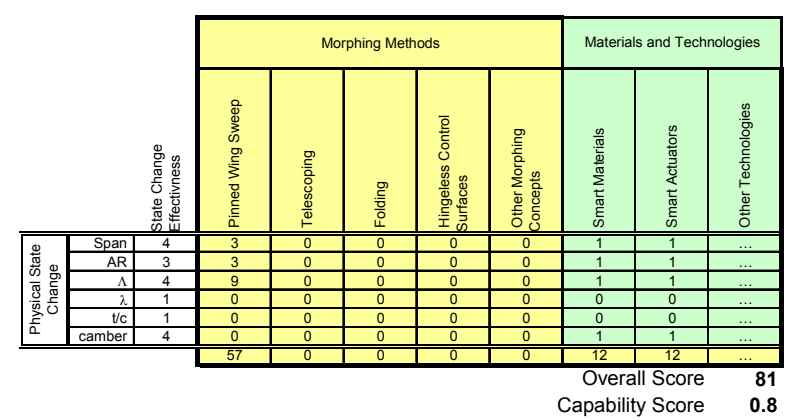

Aircraft \#1

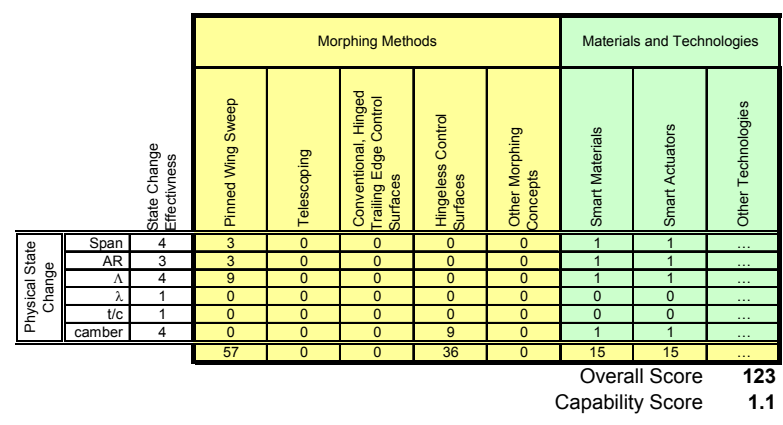

Aircraft \#2

Figure 8-MCoA Step 2/Part 2: Connecting morphing methods and technologies to state changes

Step 3 in the MCoA process is simply plotting the relative scores from the three previous steps onto a three-axes plot, Figure 10. One axis is the mission performance impact (MPI), another the morphing capability score (MCS), and the third is a measure of the risk assessment. This plot allows a graphical comparison of each vehicle in terms of its performance, morphing capability, and risk for a desired mission. Initially, the goal of the MCoA tool was to arrive at a single number that could be used to rank morphing concepts. With continuing development of this assessment process, it has become clear that one number provides little information in terms of assessing performance benefits, morphing ability, or risk associated with morphing concepts. In lieu of this single number, the graphical representation shows how the vehicles compare in the three critical areas.

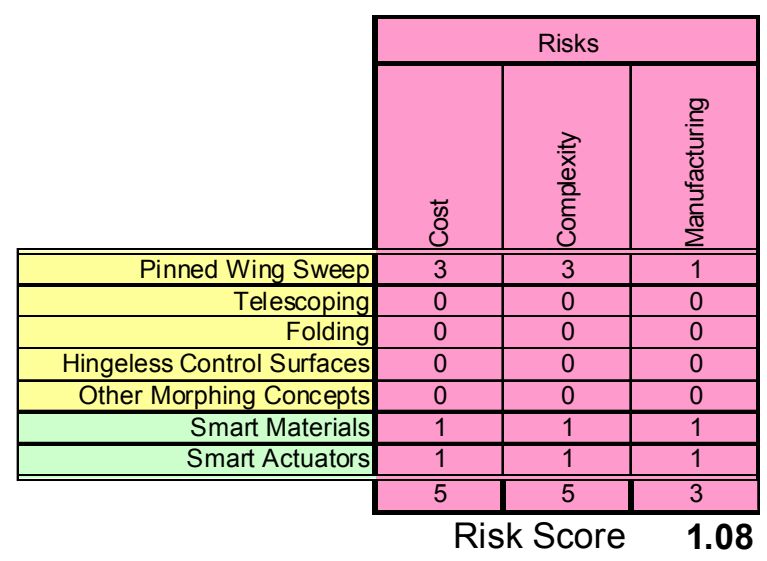

\section{Aircraft \#1}

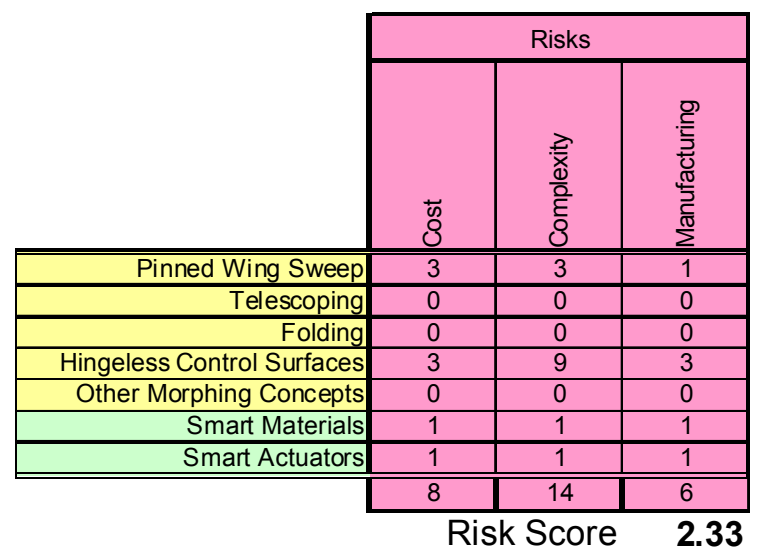

\section{Aircraft \#2}

Figure 9-MCoA Step 2/Part 3: Risk assessment

To help make the comparison between vehicles easier, the plots can be unfolded and the projection of each side of the triangle plotted. The projection plots are shown in Figure 11. The projection plots may be especially useful during technology development phases for which adequate information may not be readily available to complete the entire assessment. As can be seen from Figures 11 and 12, Aircraft \#2 scores higher in all the categories including risk.

American Institute of Aeronautics and Astronautics 


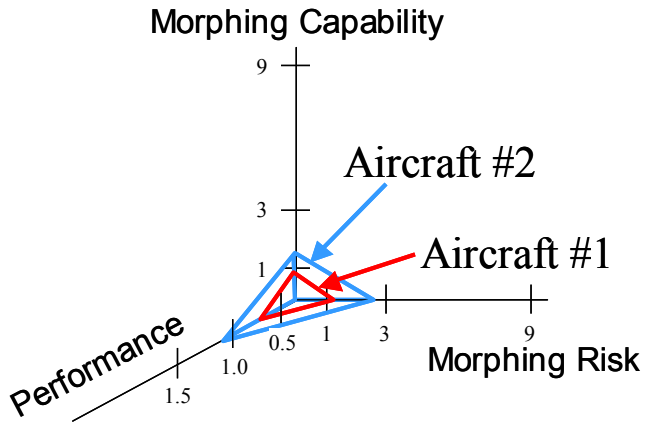

Figure 10-MCoA Step 3: Comparison of different morphing concepts

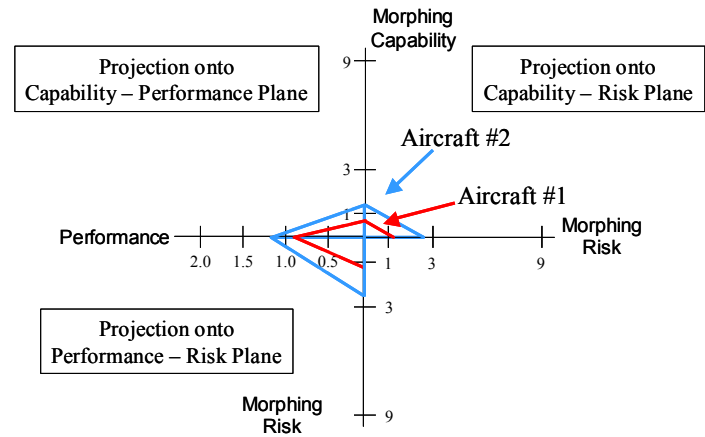

Figure 11-Projection plots for morphing capability of the different vehicles

\section{Morphing Concept Development Levels (MCDL)}

While the MCoA tool provides the ability to assess proposed vehicle and technology concepts relative to achieving desired mission capabilities, the MCDL chart is intended to provide a broader, qualitative view of morphing capabilities and goals for future vehicle systems. It must present the progression of key attributes to a final set of desired features based on the morphing vehicle system objectives. These objectives must be set a priori as a reflection of a long-term vision on morphing development. Thus, the MCDL could serve as a program-planning tool to indicate general directions and goals for technology and vehicle system morphing capability advancement.

The vehicle system attributes to be considered in the MCDL are grouped in two sets of features: vehicle type-independent and vehicle specific. Figure 12 presents an initial representation of such chart and its feature development phases. In this particular case, the vehicle specific features are considered for an air vehicle. Ranging from no special feature to a full morphing realization, each feature stream (column) is subdivided in ten levels.

The vehicle independent features describe desired characteristics of a vehicle independent of its operational environment (i.e., air, water, land, space, or some combination of them). The mission effectiveness column captures the desire to perform existing missions and combinations of existing missions, as well as to enable new missions. It is also desired that the vehicle present great adaptability to the environment and threats. Since the focus to achieve these features is through state changes, the morphing development should progress in such a way that will eventually lead to large state changes. Finally, overall cost assessment of the methods employed in the morphing realization, from component to the system level, must be such that it provides great improvements over existing methods.

The vehicle specific part of the MCDL chart is much more complex to establish. It involves the identification of key features that characterize the vehicle class (i.e., operational media) under consideration. Once such characteristics are defined, envisioned phases of development ranging from those requiring no special features to those required for a complete morphing vehicle must be developed for each of those key features. As a first attempt to identify some of these key features and their envisioned developmental stages towards a complete morphing air vehicle, three specific features are proposed: lift generation surfaces, means of maneuvering (represented in the chart under the column "Maneuvering Capability"), and survivability/ maintainability, particularly during flight operations. Inspired in biological systems, the desired morphing aircraft would conformably deploy lifting surfaces, provide high-bandwidth maneuver forces and moments, and present adaptability/maintainability on demand. These vehicle-specific streams are very important to help guide the research investment for development of specific features associated with a vehicle being operated in given media. In contrast, the vehicle independent features are what ultimately need to be present in a new system that will satisfy the stated needs.

To aid in general program planning, it is essential that morphing concepts be assessed in terms of a highlevel vision of the desired features of the weapon system. Consider the MCDL chart presented in Figure 12 as an initial representation of that high-level vision. In the context of the example above, Aircraft \#2 presents certain key vehicle features that can be mapped into the MCDL chart. These are shown by the dashed dots and lines in Figure 12. The advanced strike/attack mission can be seen as a level 3 under "Mission Effectiveness." Similarly, the camber changes are reflected as small state changes in the context of morphing state changes. Although the extra maneuverability provided by the small reshaping of the wing increases its survivability, the vehicle provides minimum adaptability to the environment and/or threats, reflecting in a level 2 score in the corresponding column in the MCDL chart. 


\begin{tabular}{|c|c|c|c|c|c|c|c|}
\hline \multirow[b]{2}{*}{ Level } & \multicolumn{3}{|c|}{ Vehicle-independent Features } & \multirow[b]{2}{*}{$\begin{array}{l}\text { Generalized Cost (\$, weight, } \\
\text { complexity, power, reliability) }\end{array}$} & \multicolumn{3}{|c|}{ Vehicle-specific Features } \\
\hline & Mission Effectiveness & State Change/Efficiency & $\begin{array}{l}\text { Adaptability to Environment } \\
\text { and/or Threat }\end{array}$ & & Lift Generation Surfaces & Maneuvering Capability & Survivability/Maintainability \\
\hline 10 & $\begin{array}{l}\text { Enable new missions } \\
\text { with superior } \\
\text { effectiveness }\end{array}$ & $\begin{array}{l}\text { Large state change - exceeds } \\
\text { performance of existing } \\
\text { methods }\end{array}$ & $\begin{array}{l}\text { Great adaptability to } \\
\text { environment and//or threat- } \\
\text { cannot be done with other } \\
\text { methods }\end{array}$ & $\begin{array}{l}\text { Great improvement over } \\
\text { existing methods - from } \\
\text { component to system levels }\end{array}$ & $\begin{array}{l}\text { Conformally deployed liftting } \\
\text { surfaces on demand }\end{array}$ & $\begin{array}{l}\text { High-bandwidth maneuver } \\
\text { forces and moments on } \\
\text { demand }\end{array}$ & $\begin{array}{l}\text { Adaptability/maintainability on } \\
\text { demand }\end{array}$ \\
\hline 9 & $\begin{array}{l}\text { Enable new mission with } \\
\text { improved effectiveness }\end{array}$ & $\begin{array}{l}\text { Large state change - } \\
\text { competes with existing } \\
\text { methods }\end{array}$ & $\begin{array}{l}\text { Great adaptability to } \\
\text { environment and/or threat- } \\
\text { exceeds performance of } \\
\text { existing methods }\end{array}$ & $\begin{array}{l}\text { Great improvement over } \\
\text { existing methods - at the } \\
\text { weapon system level }\end{array}$ & & & Self-healing systems \\
\hline 8 & Enable new mission & $\begin{array}{l}\text { Large state change - } \\
\text { inefficiently replaces existing } \\
\text { methods }\end{array}$ & $\begin{array}{l}\text { Great adaptability to } \\
\text { environment and/or threat- } \\
\text { competes with existing methods }\end{array}$ & $\begin{array}{l}\text { Competes with existing } \\
\text { methods - at the weapon } \\
\text { system level }\end{array}$ & & $\begin{array}{l}\text { Conformally deployed control } \\
\text { surfaces from wing-fuselage }\end{array}$ & \\
\hline 7 & $\begin{array}{l}\text { Combining (dissimilar) } \\
\text { existing missions with } \\
\text { superior effectiveness }\end{array}$ & $\begin{array}{l}\text { Moderate state change - } \\
\text { exceeds performance of } \\
\text { existing methods }\end{array}$ & \begin{tabular}{|l|} 
Moderate adaptability to \\
environment and/or threat- \\
cannot be done with other \\
methods
\end{tabular} & $\begin{array}{l}\text { Inneficient w.r.t. existing } \\
\text { methods - at the weapon } \\
\text { system level }\end{array}$ & & & \\
\hline 6 & $\begin{array}{l}\text { Combining (dissimilar) } \\
\text { existing missions with } \\
\text { improved effectiveness }\end{array}$ & $\begin{array}{l}\text { Moderate state change - } \\
\text { competes with existing } \\
\text { methods }\end{array}$ & $\begin{array}{l}\text { Moderate adaptability to } \\
\text { environment and/or threat- } \\
\text { exceeds performance of } \\
\text { existing methods }\end{array}$ & $\begin{array}{l}\text { Great improvement over } \\
\text { existing methods - at the } \\
\text { vehicle level }\end{array}$ & $\begin{array}{l}\text { Hybrid local and global lifting } \\
\text { surface characteristics change }\end{array}$ & & $\begin{array}{l}\text { Adaptive reconfiguration integrated } \\
\text { with vehicle health management } \\
\text { system }\end{array}$ \\
\hline 5 & $\begin{array}{l}\text { Combining (dissimilar) } \\
\text { existing missions } \\
\text { inefficiently }\end{array}$ & $\begin{array}{l}\text { Moderate state change - } \\
\text { inefficiently replaces existing } \\
\text { methods }\end{array}$ & $\begin{array}{l}\text { Moderate adaptability to } \\
\text { environment and/or threat- } \\
\text { competes with existing methods }\end{array}$ & $\begin{array}{c}\text { Competes with existing } \\
\text { methods - at the vehicle level }\end{array}$ & $\begin{array}{l}\text { High- to short-aspect ratio } \\
\text { conformal lifting surface change } \\
\text { (and vice-versa) }\end{array}$ & $\begin{array}{l}\text { High bandwidth large scale } \\
\text { lifting surfaces shape } \\
\text { changes for flight control in } \\
\text { multiple axes }\end{array}$ & $\begin{array}{l}\text { Aircraf re-trimming after } \\
\text { failure/damage, store/load changes, } \\
\text { etc. }\end{array}$ \\
\hline 4 & $\begin{array}{l}\text { Perform existing } \\
\text { missions with superior } \\
\text { effectiveness }\end{array}$ & $\begin{array}{l}\text { Minimal state change - } \\
\text { exceeds performance of } \\
\text { existing methods }\end{array}$ & $\begin{array}{l}\text { Minimal adaptability to } \\
\text { environment and/or threat- } \\
\text { cannot be done with other } \\
\text { methods }\end{array}$ & $\begin{array}{c}\text { Inneficient w.r.t. existing } \\
\text { methods - at the vehicle level }\end{array}$ & $\begin{array}{l}\text { Conformal lifting surfaces } \\
\text { sweep and/or surface area } \\
\text { change }\end{array}$ & $\begin{array}{l}\text { High bandwidth lifting surface } \\
\text { shape changes for primary } \\
\text { flight control in roll and pitch } \\
\text { axes, secondary in yaw }\end{array}$ & $\begin{array}{l}\text { Vehicle real-time reconfigurable } \\
\text { flight envelop based on usage and } \\
\text { health monitoring information }\end{array}$ \\
\hline 3 & $\begin{array}{l}\text { Perform exisjing - - - } \\
\text { missions with improved } \\
\text { effectiveness }\end{array}$ & $\begin{array}{l}\text { Mimimat state cbange - } \\
\text { competes with existings - } \\
\text { methods }\end{array}$ & $\begin{array}{l}\text { Provides minimal adaptability to } \\
\text { environment and/or threat- } \\
\text { exceeds performance of } \\
\text { existing methods }\end{array}$ & $\begin{array}{l}\text { Great improvement over } \\
\text { existing methods - at the } \\
\text { component level }\end{array}$ & $\begin{array}{l}\text { Local (camber, thiickness) airfoil } \\
\text { shapte chänges }\end{array}$ & 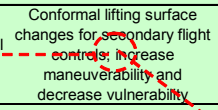 & In-flight active loads re-distribution \\
\hline 2 & $\begin{array}{l}\text { Perform existing } \\
\text { missions with current } \\
\text { effectiveness }\end{array}$ & $\begin{array}{l}\text { Minimal state change - } \\
\text { inefficiently replaces existing } \\
\text { methods }\end{array}$ & $\begin{array}{l}\text { Provides mimpimal adaptability to } \\
\text { environment and/9r threat- } \\
\text { competes with éxisting mometheds }\end{array}$ & $\begin{array}{c}\text { Competes with existing } \\
\text { methods - at the component } \\
\text { level }\end{array}$ & $\begin{array}{l}\text { Discrete lifting surface sweep } \\
\text { and/or area change }\end{array}$ & $\begin{array}{l}\text { Conformal lifting surface' } \\
\text { changes driven by discrete } \\
\text { surfaces }\end{array}$ & Vethicle usage and health monitoring \\
\hline 1 & $\begin{array}{l}\text { Perform existing } \\
\text { missions inefficiently }\end{array}$ & No state change & \begin{tabular}{|l|} 
Provides minimal adaptability to \\
environment and/or threat- \\
inefficiently replaces existing \\
methods
\end{tabular} & 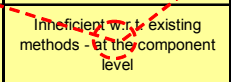 & Conventional fixed surfaces & No special features & No speciál features \\
\hline
\end{tabular}

Figure 12- Morphing Concept Development Levels (with specific features for morphing air vehicles)—dashed lines indicate key features as being captured by Aircraft \#2

Considering that the physical realization of the camber change mechanisms for Aircraft \#2 follows the one used in the AFTI F-111, the additional mechanical complexity and potential weight penalty will have a negative impact on generalized costs. This would be indicated in Figure 12 as a level 1 score. In terms of vehicle-specific features, Aircraft \#2 does provide an advance on the lift generation surface features, thereby achieving level 3 due to the presence of airfoil shape change associated with camber deformation. This also provides an increase in maneuverability and changes in secondary flight controls through adjusting the wing shape through different mission segments. Finally, Aircraft \#2 does not present any special feature for improved maintainability or survivability.

With these results, if the Aircraft \#2 concept goes forward and is developed, progress will be made in certain features that support the morphing objectives (as indicated in the MCDL chart, Figure 12). On the other hand, such a program will not address certain key features that will be part of a complete morphing aircraft and new development programs in those areas will be necessary to attain the complete morphing objectives. By representing different programs using this common framework and process, program managers and researchers will see which features are being developed and which ones are lagging and need more attention. In the example above, that may drive the funding allocation for new programs to issues associated with integrated vehicle health management systems, as a next step towards further development on survivability/maintainability (since this is still at level 1 in Figure 12).

\section{CONCLUDing REMARKS}

This paper presents a proposed structure and process for performing a morphing capability assessment. The impetus behind developing this framework is to help technologists, system developers, and program managers to better discern and track the development of morphing vehicle technologies. The proposed framework consists of two distinct but interconnected parts: the Morphing Concept Assessment tool and the Morphing Concept Development Level chart.

The MCoA tool, in its current form, utilizes knowledge of the desired mission and the quality functional deployment tool methodology to calculate three numbers that can be used to evaluate morphing "success" as it applies to a pre-determined mission.

The MCDL chart contains general morphing vehicle system features and the corresponding envisioned development stages towards a complete morphing vehicle realization. It may also guide and track morphing capability developments. A preliminary 
example of a MCDL chart for a general morphing air vehicle was presented. However, it still needs further refinements to represent all the key features desired in morphing vehicles. Once this is accomplished, the MCDL chart could support investment decisions for future $R \& D$ programs.

While many potential pit-falls have been identified and addressed, the MCA components are not complete and validated, and future efforts should include testing the MCA framework on more representative examples, perhaps the DARPA Morphing Aircraft Structures (MAS) designs and other concepts under development by agencies such as NASA or ONR.

\section{ACKNOWLEDGEMENTS}

The authors would like to thank Dr. Terry Weisshaar of DARPA, Mr. Bill Horn of NavAir, and Dr. Yevgeny Macheret and Dr. Janet Sater of the Institute for Defense Analyses for all their support and guidance during the development of the Morphing Capability Assessment process.

\section{REFERENCES}

1. "ONR/DARPA In-Flight Reconfigurable Aircraft Workshop (Report for Workshop Held at IDA, 1011 December 2002)", Draft IDA Document D2876 (in preparation).

2. Clough, B. T., "Metrics, schmetrics! How do you track a UAV's autonomy?," AIAA-2002-3499.

3. Boeing Corporation, "AFTI/F-111 Mission Adaptive Wing Briefing to Industry", AFWALTR-88-3082, October 1988.

4. Comstock, T., and K. Dooley, "A Tale of Two QFDs", Quality Management Journal, 5(4): 32-45, 1998 